\title{
ROGER BACON, EL DIÁLOGO DE IRA DE SÉNECA Y EL LIBRO CONTRA LA IRA E SA N A*
}

\author{
Juan Héctor Fuentes \\ Instituto de Investigaciones Bibliográficas y Crítica Textual (CONICET) \\ Universidad de Buenos Aires \\ juanterm@yahoo.com
}

En un estudio anterior sugerimos la posibilidad de que el romanceamiento castellano del De ira de Séneca realizado para Sancho IV de Castilla hubiera sido compuesto entre 1292 y 1295 por un traductor conocedor de las prácticas universitarias y muy probablemente cercano al entorno del franciscano Juan Gil de Zamora $(\dagger 1318)^{1}$. Los estudios que hemos venido realizando desde entonces y, principalmente, el cotejo de la traducción con el texto latino y los comentarios marginales conservados en el ms. BnF Lat. 6390 nos han permitido corroborar la familiaridad del romanceador o del compilador con el ámbito universitario, ya que al adaptar el diálogo a la forma tractatus reorganizó el material traducido siguiendo las prácticas escolásticas textualizadas en los comentarios (accesus, diviso textus, quaestio) y las incluyó como elementos constitutivos de la obra. ${ }^{2}$ En el presente trabajo nos detendremos en estudiar la relaciones que pueden establecerse entre el Libro de Séneca contra la yra e saña y una de las figuras más destacadas del entorno intelectual franciscano del siglo XIII, el franciscano inglés Roger Bacon, conocido como Doctor Mirabilis.

\footnotetext{
* Este estudio se inscribe en el marco del proyecto de investigación: Alfonso de Cartagena. Obras Completas FFI 2014-55902-P y FFI 2017-84858-P (MINECO y MICINN, Gobierno de España).

${ }^{1}$ Juan Héctor Fuentes, «Algunas cuestiones vinculadas con el Libro de Séneca hordenado e dispuesto contra la yra e saña: fecha de composición, traductor e intencionalidad», en Letras, $48-49$ (2003-2004), pp. 60-66.

${ }^{2}$ Véase Juan Héctor Fuentes, «Sobre la organización de la materia traducida en el Libro de Séneca contra la yra e saña», en Philologiae flores: homenaje a Amalia Nocito, ed. de M. ${ }^{a}$ Eugenia Steinberg y Pablo Cavallero, Buenos Aires, Universidad, 2010, pp. 431-437, y «El Libro de Séneca contra la yra e saña y su relación con BnF ms. Latin 6390», en Atalaya, 16 (2016) [En línea]. Enlace <http://journals. openedition.org/atalaya/1843> [Consulta: 7/04/2018] DOI: 10.4000/atalaya.1843.
} 


\section{Roger Bacon y las obras enviadas a Clemente IV}

Como señalaron Reynolds ${ }^{3}$ y previamente Beeson ${ }^{4}$, Roger Bacon (1214/1220-1292) ocupa un lugar destacado en la transmisión del texto de los Diálogos de Séneca y, de modo particular, del De ira ${ }^{6}$. Dos obras son especialmente relevantes a la hora de estudiar la recepción de Séneca y de su obra dentro de la producción del Doctor Mirabilis: el Opus Maius ${ }^{7}$ y el Opus Tertium $^{8}$, compuestas a instancias del papa Clemente IV (1265-1268) ${ }^{9}$, quien en junio de 1266 dirigió una carta al franciscano para que pusiera por escrito «quae tibi videntur adhibenda remedia circa illa, quae nuper occasione tanti discriminis intimasti: et hoc quanto secritus poteris facias indilate» ${ }^{10}$. En respuesta al pedido del papa, Bacon rápidamente compone una obra introductoria, el Opus maius, seguida de dos obras estrechamente relacionadas con ella, el Opus minus y el Opus tertium. La primera, llamada también Opus primum, principale -en contraste con el Opus minus o secundum- o Tractatus praeambulus, en vistas de una enciclopedia general de las ciencias que nunca llegó a componer ${ }^{11}$, está formada por siete partes de desigual longitud en las que trata los siguientes temas: 1) sobre las causas de la ignorancia humana; 2) sobre la relación entre Filosofía y Teología; 3) sobre el conocimiento de las

\footnotetext{
${ }^{3}$ Leighton D. Reynolds, «The Medieval Tradition of Seneca's Dialogues», en The Classical Quarterly, New Series, 18:2 (1968), pp. 360-363.

${ }^{4}$ Charles H. Beeson, «Roger Bacon and the Dialogues of Seneca», en The Manly Anniversary Studies in Language and Literature, Chicago, University Press, 1923, pp. 243-253.

${ }^{5}$ Sobre Roger Bacon y su obra véase Eugenio Massa, Ruggero Bacone. Etica e poetica nella storia dell' «Opus Maius», Roma, Edizioni di Storia e Letteratura, 1955; Franco Alessio, Introduzione a Ruggero Bacone, Roma, Laterza, 1985; Roger Bacon \& the Sciences. Commemorative Essays, ed. de Jeremiah Hackett, Leiden, Brill, 1997; Jeremiah Hackett, «Roger Bacon», en Stanford Encyclopedia of Philosophy, Stanford, University, 2013. [En línea]. Enlace: $<$ https://plato.stanford.edu/entries/roger-bacon/ $>$ [Consulta: 2/05/2018]; Amanda Power, Roger Bacon and the Defense of Christendom, Cambridge, University Press, 2013.

${ }^{6}$ Reynolds, art. cit., pp. 362-363, destaca asimismo la importancia de Gilberto de Tournai (1209$1284)$ y de Juan de Gales ( $† 1285)$, también frailes que residieron en París en el tercer cuarto del siglo XIII, como testigos de la tradición de los Dialogi.

${ }^{7}$ The 'Opus majus' of Roger Bacon, 3 vols., ed. de John Herny Bridges, vols. 1-2, Oxford, University Press, 1897; vol. 3, Edinburgh, William \& Norgate, 1900.

${ }^{8} \mathrm{Fr}$. Rogeri Bacon, Opera quaedam hactenus inedita, vol. I containing I Opus tertium, II Opus minus, III Compendium philosophiae, ed. de J. S. Brewer, London, Longman, Green, Longman \& Roberts, 1859 , pp. 3-310.

${ }^{9}$ Reproducida por Bridges, ed. cit., p. 1, n. 1.

${ }^{10} \mathrm{Ed}$. cit., p. 2. [«los remedios que según tu parecer deben aplicarse a aquellos peligros que, recientemente, ante una situación tan crítica, supiste señalar. Y haz esto sin dilación tan secretamente como puedas»]. La traducción de los pasajes latinos es de mi autoría.

${ }^{11}$ Véase Part of the Opus Tertium of Roger Bacon, including a Fragment Now Printed of the First Time, ed. de Arthur George Little, Aberdeen, University Press, 1912, pp. VIII-IX; e Id., Roger Bacon Essays, Oxford, Clarendon Press, 1914, pp. 11-12.
} 
lenguas; 4) sobre la utilidad de las Matemáticas; 5) sobre la ciencia óptica; 6) sobre la ciencia experimental y 7) sobre la filosofía mora ${ }^{12}$. Antes de finalizar su Opus maius, Bacon compone el Opus minus ${ }^{13}$, atendiendo a la posibilidad de que la obra principal se perdiera en el camino, a la necesidad por parte del papa de contar con una versión resumida del tratado y al hecho de que algunas cuestiones habrían sido omitidas en el primer escrito o no habrían estado en condiciones de ser incluidas ${ }^{14}$. Las obras fueron enviadas al pontífice junto con el De multiplicationes specierum y un tratado sobre alquimia. Por las mismas razones que llevaron a Bacon a escribir el Opus minus compuso también un Opus tertium hacia 1267, aunque no hay evidencia de que el tratado hubiera llegado al papa, quien falleció el 29 de noviembre de 1268.

\section{Séneca en el Opus maius}

En las obras mencionadas el franciscano inglés manifiesta una profunda admiración por Séneca, reconociendo en él y en todos los filósofos antiguos la forma acabada de exposición propia de la filosofía moral, la cual perfecciona no solo el intelecto sino también la voluntad y proporciona un conocimiento por encima de todo práctico. Siguiendo a Aristóteles, sostiene que el discurso es el mejor remedio para inclinar la mente de los hombres y el argumento retórico, el propio de la moral ${ }^{15}$. Como los textos aristotélicos que desarrollaban dicho argumento, la Retórica y la Poética, aún no habían alcanzado una suficiente difusión entre los escolásticos y los esquemas argumentativos que brindaba Cicerón en su retórica no le satisfacían, Bacon encuentra en la obra de Séneca la principal fuente de su filosofía moral, a la que consagra la totalidad de la parte VII del Opus maius ${ }^{16}$. El franciscano entiende la Moralis philosophia como la ciencia «que melior est et nobilior omnibus predictis et hec est inter omnes practica, id est operativa, et de operibus nostris in hac

${ }^{12}$ Little, ed. cit., p. IX.

${ }^{13}$ Brewer, ed. cit., pp. 311-389.

${ }^{14}$ Véase Ibid., pp. 5 y 42-43, y Little, ed. cit., p. Ix.

15 Véase Rogeri Baconis Moralis Philosophia, ed. de Eugenio Massa, Zürich, Thesaurus Mundi, 1953, p. XxIV. Un estudio sobre la metología empleada por Bacon y el lugar de la filosofía moral en su sistema en Antonino Poppi, «La metodologia umanistica de la Moralis philosophia di Ruggero Bacone», en Schede Medievali, 24-25 (1993), pp. 149-167.

${ }^{16}$ Véase Bridges, ed. cit., vol. 2, pp. 223-404 y Massa, ed. cit., p. xxIV, y ob. cit., p. 138. Al respecto afirma Bacon: «Hoc autem argumentum non est notum vulgo artistarum apud latinos, quoniam libri Aristotilis et suorum expositorum nuper translati sunt et nondum sunt in usu studencium; [...] indigemus completa doctrina Aristotilis et commentatorum eius» [«Este argumento no es conocido por la mayor parte de los maestros de artes entre los latinos puesto que los libros de Aristóteles y de sus expositores han sido traducidos recientemente y aún no están a disposición de los estudiosos; [...] carecemos de la enseñanza completa de Aristóteles y de sus comentadores»]. Massa, ed. cit., p. 251. 
vita et in alia constituta» ${ }^{17}$. La parte VII, organizada a su vez en cinco partes, presenta en sus dos primeras el objeto y el método de la filosofía moral junto con un esbozo de antropología filosófica basado en Platón, Aristóteles, los estoicos y San Agustín (Parte I) y una breve exposición sobre la estructura social de la vida inspirada en Avicena (Parte II). La tercera parte del libro, la más sustancial, hace referencia a la virtud y el vicio y está formada por citas extraídas principalmente de Séneca y Cicerón, presentadas a la manera de una antología comentada ${ }^{18}$ :

Tercia vero pars Scientie moralis et civilis est de moribus cuiuslibet persone secundum se, ut honestas vite in quolibet habeatur et turpido viciorum relinquatur propter futuram felicitatem et horrorem eterne pene ${ }^{19}$.

En esta parte se destaca la distinctio tercia, un verdadero tratado sobre la ira organizado en un proemio y nueve partes, que está compuesto, casi en su totalidad, por una compilación de pasajes del De ira de Séneca ${ }^{20}$. El interés de Bacon por esta sección se evidencia también por el hecho de que el ms. Vat. Lat. 4295 conserve anotaciones del franciscano en sus márgenes ${ }^{21}$.

\footnotetext{
${ }^{17}$ Ed. cit., p. 3. [ «[la ciencia] que es mejor y más noble que todas las mencionadas y esta es, entre todas, práctica, es decir, operativa, y se fundamenta en las obras de nuestra vida presente y de la otra»].

${ }^{18}$ Véase Hackett, ob. cit., pp. 16 y 56.

${ }^{19}$ Massa, ed. cit., p. 45. [«La tercera parte de la ciencia moral y civil es sobre las costumbres de cualquier persona en sí mismas, de modo que en cualquiera se mantenga la honestidad de vida y se deje la torpeza de los vicios en función de la felicidad futura y del horror de la pena eterna.»].

${ }^{20}$ Ed. cit., pp. 72-103.

${ }^{21}$ Véase ed. cit. pp. X-XII. En su Opus Tertium el mismo Bacon comenta su actividad como corrector y anotador: «Quae de ira scripsi plana sunt, quia correxi ilia et signavi. Alia vero quae sequuntur non ita patent, quia non sunt correcta nec signata; propter quod modo mitto exemplar correctum» (Brewer, ed. cit., p. 305) [«Lo que escribí sobre la ira es claro, porque lo corregí y anoté. En cambio, lo que va a continuación no está tan claro porque no fue ni corregido ni anotado, por lo cual solo envío el ejemplar corregido»]. Y en el fragmento editado por primera vez por Duhem: «Et hec correxi diligenter, et posui signa exterius [f. 193r], ut facilius electiores sententie notarentur. Deinde, intuli multa alia preclara de magnanimitate, et constantia animi, et patientia in rebus adversis, et de contemptu earum, et de vite perfectione, quam Seneca vocat beatitudinem, et de tranquillitate animi obtinenda, et de multis aliis, in quibus posui sententias multorum librorum Senece, qui optimi sunt, et rarissime inveniuntur. Sed hec alias non potui corrigere propter superfluitatem occupationum. Et ideo nunc mitto exemplar correctum, ut Johannes cum suis sociis corrigat ea que remanserant incorrecta», Little, ed. cit., p. 61. [«Esto lo corregí diligentemente y puse signos externos para que se noten con más facilidad las sentencias más escogidas. Luego incorporé muchos otros pensamientos brillantes sobre la magnanimidad, la constancia del ánimo y la paciencia en las situaciones adversas y sobre su menosprecio, y sobre la perfección de la vida, que Séneca llama felicidad, y sobre la obtención de la serenidad del ánimo y sobre otras muchas cosas en las que agregué pensamientos de muchos libros de Séneca, que son óptimos y muy raros de hallar. Pero estas últimas no pude corregir por estar desbordado en mis ocupaciones. Y por eso ahora envío un ejemplar corregido, para que Juan con sus compañeros corrija aquellas cosas que quedaron sin corregir»].
} 


\section{Opus maius, Pars VII, Distincio tercia: sobre la ira}

Como hemos mencionado, la Distincio tercia de la tercera parte de la Moralis philosophia (=Opus maius, VII) está concebida como un verdadero tratado sobre la ira en el cual el Doctor Mirabilis compila pasajes procedentes, como hemos mencionado, del diálogo De ira de Séneca, a los que suma extractos del De clementia y de obras de otros autores, como Cicerón, Plinio, Jerónimo, etc. Está organizada en un Proemium y nueve capítulos. A continuación ofrecemos un esquema de su disposición con los pasajes utilizados ${ }^{22}$.

\section{Distincio tercia}

Proemium [1-2] Luego de referirse a los pecados que provienen de las situaciones prósperas se detiene en las situaciones adversas y en cómo la ira lucha contra ellas, y anuncia que hará una exposición sobre sus remedios para luego pasar a tratar sobre la paciencia frente a las adversidades.

Capítulo I [1-4] La ira es contraria a la naturaleza humana (De ira, I, 5, 1; I, 5, 3; I, 5, 2-3; I, 1, 5-6; III, 4, 3); [5-9] destruye y confunde al hombre (I, 1, 1. II, 35, 3-4; II, 35, 5; III, 3, 2; III, 4, 1-2); [10] afecta al hombre en lo corporal con pasiones y enfermedades (II, 36, 4); [11-13] se opone a la naturaleza humana también en cuanto a las partes especulativa y práctica del alma intelectiva (I, 18, 1-2; I, 19, 1-2); [14-16] conduce a la locura (II, 36, 4-5; III, 3, 3; I, 1, 3-4).

Capítulo II [1-2] Así como la ira se opone a la parte especulativa del alma, del mismo modo se opone a la práctica, ya que la ira como vicio se opone a la virtud. Luego de presentar el tema citando las Epistolas de Séneca, a Cicerón (De off, II, 10, 35 y Tusc, II, 14, 32 y III, 8, 17) y nuevamente a Séneca (De ira, II, 12, 2) pasa a contraponer la ira con la virtud de la clemencia [3-14], para lo cual, luego de hacer una referencia al libro IV de la Ética de Aristóteles (IV, II, 1125b, 29 ss.), incorpora una extensa serie de pasajes del De clemencia en los cuales destaca la importancia de esta virtud para reyes y príncipes $^{23}$ (De clem., I, 3, 2; II, 4, 1; I, 3, 3; I, 3, 3; I, 5, 6; I, 7, 1; I, 7, 2; I, 11, 2; I, 11, 2; I, 11, 4; I, 11, 4; I, 12, 3; I, 13, 2; I, 13, 4; I, 13, 5; I, 19, 2-3; I, 19, 4; I, 19, 5-7; I, 20, 2-3; I, 20, 3; I, 24, 1; I, 24, 2; I, 2, 1). [15-27] Se detiene en la relación de la ira con el resto de las virtudes, comenzando por la magnanimitas, «ornatum omnium virtutum» (Arist., Eth. Nic., IV, 7, 1124 a , 1-2), para lo cual incluye pasajes del De ira, de la Formula honestae vitae de Martín

\footnotetext{
${ }^{22}$ Seguimos la edición de Massa, ed. cit. Los números en negrita entre paréntesis remiten a la capitulación incluida por el editor.

${ }^{23}$ Para lo cual se apoya también en Reg. III, 20, 31: «los reyes de la casa de Israel son clementes».
} 


\section{Juan Héctor FuENTES}

Dumiense (obra atribuida a Séneca durante la Edad Media), del De clementia y de las Naturales quaestiones: De ira, II, 32, 3; Mart. Dum., Form. hon. vit., 3, 2; De ira, II, 34, 1; I, 13, 15; III, 9, 5; II, 5, 7-8; III, 6, 1; III, 6, 2; De clem. II, 5, 4; I, 20, 3; De ira, II, 32, 3; III, 6, 1; III, 25, 3; III, 40, 124; I, 20, 1-2; I, 20, 3; I, 20, 5; Nat. Quaest., IV, 2, 14-15. La mayor parte de las citas empleadas hacen referencia a los monarcas y príncipes, bien señalándoles la conveniencia de la clemencia («nullam ex omnibus virtutibus homini magis convenire quam clemenciam, cum sit nulla humanior» ${ }^{25}$; «nullum clemencia magis quam regem et principem decet ${ }^{26}$ ), bien evidenciando la nocividad de la ira («Nam, ut dicit Seneca, pestifera vis est ad nocendum; illius demum magnitudo stabilis atque fundata est, que[m] omnes tam supra se esse quam pro se sciunt: quo procedente, non tanquam noxium animal diffigiunt, set tanquam ad clarum ac beneficum sidus certatim advolant». Et addit quod «non decet regem seva ne inexorabilis ira»; principem «talem civibus se esse velit, qualem Deum sibi $\rangle^{27}$ ). Bacon mediante notas marginales resalta la importancia de la temática para los prelados y los príncipes: «pro prelatis et principibus» ${ }^{28}$, «Nota exemplum optimum pro prelatis et principibus $»^{29}$, «Nota de magnanimitate por prelatis et principibus $»^{30}$.

Capítulo III [1] La ira se opone a la misericordia. La sección se inicia con un exemplum de la historia romana, el ruego de Cicerón a César por Marcelo: «Tullius quidem, Cesarem rogans por Marcello ut ei parceret ait: "Nulla de tuis virtutibus plurimis nec admirabilior nec gracior est misericordia; homines ad Deum nulla re propius accedunt quam salutem homibus dando. Nichil habet fortuna tua maius quam ut possis, nec natura tua melius quam ut velis servare plurimos"» (Cic., Pro Ligario, XII, 37) ${ }^{31}$. [2-9] A continuación siguen pasajes de los libros III y II del De ira: III, 24, 2-3; III, 24, 3-4; III, 25, 2; III, 26, 3-4; III, 26, 4-5; III, 27, 1-3; II, 10, 2; II, 10, 4; II, 10, 6-7.

\footnotetext{
${ }^{24}$ Massa omite la identificación del pasaje.

${ }^{25}$ [«De todas las virtudes ninguna conviene más al hombre que la clemencia, ya que ninguna es más humana que ella»].

${ }^{26}$ [«A nadie conviene más la clemencia que al rey y al príncipe»].

${ }^{27}$ [«En efecto, como dice Séneca, destructora es la fuerza para el daño. Finalmente es estable y bien fundada la grandeza de aquel a quien todos reconocen que está por encima de ellos. Cuando se presenta, no huyen de él como si fuera un animal dañino, antes bien se apresuran por acercarse como si fuera una estrella luminosa y benéfica». Y agrega que «no conviene al rey la ira cruel e inexorable», «querría que el príncipe fuera para sus ciudadanos como Dios es para él»].

${ }^{28}$ Ed. cit., p. 78.

${ }^{29}$ Ibid., p. 79.

${ }^{30}$ Ibíd., p. 81.

${ }^{31} \mathrm{Ibid}$., p. 84. No identificado por Massa. [«Tulio, ciertamente, rogando a César por Marcelo para que lo perdonara dice: «Ninguna de tus numerosas virtudes es más admirable ni graciosa que la misericordia. Los hombres por ninguna otra cosa se acercan más a Dios que dando salvación a los hombres. Nada es más grande para tu fortuna que el poder conservar a muchos; ni para tu naturaleza, el querer conservarlos»].
} 
Capítulo IV

[1-2] La ira se opone a la piedad, a la paciencia, al gozo y a la paz del corazón. [3-4] La ira destruye no solo los bienes espirituales y corporales del hombre, sino también a los que lo rodean, de modo particular, a los amigos (De ira, II, 36, 5; II, 23, 1; II, 36, 5). A través de exempla de la antigüedad, Bacon se preocupa en remarcar cómo afecta esta situación especialmente a los gobernantes [5-9]: De ira, II, 23, 1; III, 14, 1; III, 14, 2; III, 15, 1; III, 16, 3; III, 17, 1; III, 17, 2; III, 17, 3; Nat. Quaest., VI, 23, 2-3; Plin., Nat. Hist., XXX, 16, 149. [10-11] La ira disipa las riquezas: De ira, II, 36, 6; II, 36, 5. [12-14] La ira ofende a Dios: De ira, II, 27, 1-2; I, 20, 8; I, 20, 9.

Capítulo V [1-9] La ira excede en malicia al resto de los pecados (De ira, III, 5, 3-4; III, 5, 5; III, 1, 3; III, 1, 3-5; III, 2, 1; III, 2, 2-3; I, 2, 1-2; III, 5, 3).

Capítulo VI [1-10] Ejemplos de sabios y grandes príncipes (exempla sapientium et magnificorum principum) que muestran cómo el hombre puede apartar de sí la ira: Solino, Coll. rer. Mem., I, 73; De ira, II, 7, 1; II, Aulo Gelio, Noct. Att., I, 17, 1-3; Jerónimo, Contra Jov., I, 48; Casiano, Collatio XIII, De protec. Dei, 5; De ira, I, 15, 3; III, 11, 2; III, 12, 5; III, 12, 6; III, 12, 6-7; II, 21, 10; Cic., Tusc., IV, 36; Eusebio, Chronicon; De ira, III, 38, 1; III, 38, 7-11; III, 389, 13, 15; II, 10, 5.

Capítulo VII [1-13] Exempla de gobernantes de la antigüedad, tomados exclusivamente del De ira: III, 14, 2; III, 14, 5; III, 15, 1; III, 15, 2; III, 16, 2; III, 22, 2-5; III, 23, 2; III, 23, 3; II, 23, 2; II, 23, 3; III, 11, 4; II, 32, 2; II, 23, 4; III; 23, 4-5; III, 23, 7-8; III, 24, 1. Una vez más mediante notas marginales destaca la importancia de los pasajes para los prelados y los reyes. Así en el margen inferior del folio, agrega la siguiente nota a De ira, III, 16, 232: «Notandum super omnia verbum duplici capite vallatum. Nam totus mundis perit quia hoc non observatur in prelatis et principibus. Et hoc est mors propia prelatorum et principum... $\rangle^{33}$. A lo largo del capítulo se precupa por señalar los ejemplos que corresponden a monarcas: «Nota de Philippo, rege crudeli» ${ }^{34}$; «Nota de Catone» ${ }^{35}$; «Nota de Cesare: optimum»; «Nota de Augustu Cesare, cui nemo par fuit imperio, nec Alexander, nec alius $\rangle^{36}$.

\footnotetext{
${ }^{32}$ «Set cum utilis sit servientibus affectuum suorum et huius precipue rabidi atque effreni continencia, utilior est regibus; nam perierunt omnia ubi, quantum ira suadet, fortuna permittit» [«Mas, siendo útil a los esclavos la contención de sus pasiones y, principalmente, de esta que es rabiosa y desenfrenada, con todo, es más útil a los reyes, pues todo se perdió cuando la fortuna permite cuanto lo que la ira persuade.»].

${ }^{33}$ Ibid., p. 95. [«Debe notarse sobre todo las palabras señaladas, pues todo el mundo perece porque esto no se observa en los prelados y príncipes. Y es motivo de muerte propia de los prelados y príncipes...»].

${ }^{34}$ Ibid., p. 96.

${ }^{35}$ A quien califica de magnus princeps Romanorum.

${ }^{36}$ Ibíd., p. 97.
} 
Capítulo VIII [1-11] Remedios contra la ira a partir de la consideración de su mala naturaleza y por medio de ejemplo de sabios y poderosos («ex consideracione malarum condicionum eius, deinde per exempla sapientium et potentum») ${ }^{37}$ : De ira II, 29, 2; II, 29, 3; II, 29, 4; II, 24, 1; II, 24, 1-2; III, 29, 2; III, 30, 1; II, 11, 5, III, 30, 2. Las notas marginales de Bacon enfatizan una vez más la importancia del capítulo para prelados y príncipes: «Nota iterum mortem prelatorum et principum, quo nil magis notandum», «Nota causam quare principes et prelati confunduntur ${ }^{38}$.

Capítulo IX [1-9] Segundo remedio: dilación en el cumplimiento de la pena (mora in exactione pene): De ira, II, 29, 1; III, 12, 7; III, 13, 1-3; III, 13, 4; III, 13, 6; II, 22, 2-4; III, II, 1-2. II, 31, 7. Triple argumento contra la ira (10-12): dañar a un ciudadano es un sacrilegio porque es parte de la patria (De ira, II, 31,7), porque es parte de un mismo cuerpo, la sociedad (De ira, II, 31, 7), y por la relación que se guarda con él (De ira, II, 34, 1 y II, 30, 2). La parte final del capítulo ofrece la conclusión de la distinción: «Multa vero alia sunt circa iram consideranda, que omnia principaliter patent ex libris Senece De ira et De clemencia. Set quia sermo presentis tractatus est persuasionis gracia, non scripti principalis, ideo facio finem in hiis. Habundancius vero locutus sum de hoc vicio, quia totum genus humanum semper viola(b)it et confundet, dum homo statum istius mortalitatis optinebit. Vicium enim pessimum est et maxime homini innaturale et in periculum eius excandens. Et ideo copiosius et specialius de hac parte conscripsi ${ }^{39} . \gg$

\section{Opus maius, Pars VII, Distinctio quarta y quinta: la compilatio senequista y su justificación}

Un tratamiento de la materia senequista semejante al que recibió el diálogo De ira podemos advertirlo en la Distinctio quarta: la sección está organizada en un proemium y seis capítulos consagrados a la paciencia y al desprecio de los bienes temporales, y es, como la precedente, una compilación de extractos de los diálogos De providentia (cap. 1), De constantia sapientis (caps. 2

\footnotetext{
${ }^{37} \mathrm{Al}$ comienzo del capítulo agrega en nota marginal: Nota remedia specialia contra iram.

${ }^{38}$ Ibid., p. 99.

${ }^{39}$ Ibid., p. 103. [«Ahora bien, otras muchas cuestiones quedan por considerar en torno a la ira, las cuales están expuestas en su totalidad principalmente en los libros de Séneca Sobre la ira y Sobre la clemencia. Sin embargo, puesto que la exposición del presente tratado es una persuasión y no el escrito principal [=el nombre de la enciclopedia que Bacon nunca llegó a realizar], pongo fin a esta distinción. Con todo, mis palabras sobre este vicio han sido abundantes, ya que siempre agitará y confundirá a todo el género humano en tanto el hombre mantenga su condición de mortal. En efecto, es el peor de los vicios, sumamente opuesto a la naturaleza del hombre y lo enciende para su peligro. Y por eso más abundante y específicamente escribí en esta parte»].
} 
y 3), Ad Helviam matrem (caps. 4 y 5), De remediis fortuitorum (apócrifo) (cap. 6) y Ad Marciam (cap. 7) ${ }^{40}$.

La admiración por la obra de Séneca lleva a Bacon a modificar el esquema expositivo que se había propuesto originariamente, por lo que se ve obligado a justificar su proceder en el proemio de la Distinctio quinta. La primera justificación, de orden general, se fundamenta en la «rationis vivacitas» de los clásicos ${ }^{41}$ :

Ampliavi iam hanc partem terciam Moralis philosophie ultra id quod a principio estimavi. Set delectat sentenciarum moralium pulcritudo, et precipue quia magna racionis vivacitate eruuntur per philosophorum industriam ${ }^{42}$.

El Doctor Mirabilis exalta a continuación la sabiduría práctica y las virtudes humanas de los antiguos filósofos, que contrastan grandemente con las de los cristianos, a los que considera dignos de todo vituperio y capaces de superar a los primeros solo por la Gracia de Dios:

Et tanto avidius recipiende sunt, quanto nos philosophantes christiani nescimus de tanta morum sapiencia cogitare nec tam eleganter persuadere. Utinam operibus comprobaremus ea, que ipsi philosophi nobis tam sapienter proponunt! Quamvis enim de virtutibus gratum facientibus, ut de fide, spe et caritate et huiusmodi, possumus ex professione christiana sentire que ipsi philosophi nesciverunt, tamen in virtutibus, que communiter requiruntur ad vite honestatem et ad communionem humane societatis, sermone sumus eis impares et operibus minus efficaces, sicut manifestum est ex consideracione sapiencie quam proponunt. Et hoc est satis vituperabile nobis et omni derisione dignissimum ${ }^{43}$.

\footnotetext{
${ }^{40}$ Ibid., pp. 103-132.

${ }^{41}$ Véase Massa, ob. cit., p. 86.

${ }^{42}$ Ed. cit., p. 132. [«He ampliado ya esta tercera parte de la filosofía moral más de lo que en un principio me propuse. Pero deleita la hermosura de los pensamientos morales y, principalmente, porque por la industria de los filósofos esos pensamientos salen con gran vivacidad.»].

${ }^{43}$ Ibid., p. 132. [«Y tanto con mayor avidez debemos recibirlos cuanto nosotros, filósofos cristianos, somos incapaces de meditar con tanta sabiduría de costumbres ni persuadir con igual elegancia. ¡Ojalá comprobáramos con nuestras obras aquellas cosas que los filósofos nos proponen con tanta sabiduría! (2) En efecto, aunque como por nuestra fe cristiana podemos tener noción de las virtudes santificadoras, como la fe, la esperanza, la caridad y otras por el estilo, que los filósofos desconocieron, con todo, en cuanto a las virtudes que en común son requeridas para la honestidad de la vida y la convivencia de la sociedad humana, somos distintos de ellos en cuanto a la palabra y menos eficaces en las obras, como es manifiesto por la consideración de la sabiduría que proponen. Y esto es suficiente motivo de vituperio para nosotros y muy digno de toda burla»].
} 
A la primera razón de carácter general, el franciscano añade una segunda, de carácter particular, en la que comunica al pontífice el reciente redescubrimiento de los Diálogos de Séneca:

Set et causa specialis est quod in hiis libris Senece morer; quia licet huiusmodi prosecutus sum ab infancia, tamen libros De ira, et Ad Helbiam, et Cur bonis mala accidant, et An in sapientem cadant contumelia et iniuria, et Ad Marciam, et tres adhuc sequentes non potui unquam videre nisi modo, et nescio si ad manus Vestre Glorie pervenerunt; propterea habundancius hic scribere sum conatus ${ }^{44}$.

\section{Séneca y el De ira en el Opus Tertium}

La misma actitud de Bacon hacia Séneca y los filósofos antiguos se reitera en el Opus tertium ${ }^{45}$. En la introducción (caps. I-XXI) y, más específicamente, en el cap. XIV, el franciscano hace una triple división de la filosofía moral en teológica, política y ética. Respecto de esta última afirma:

Tertia pars est de virtutum honestate ut amentur, et vitiorum turpitudine ut vitentur; et haec est pulchrior sapientia quam possit dici. Mirum enim est de nobis Christianis, qui sine comparatione sumus imperfectiores in moribus quam philosophi infideles. Legantur decem libri Ethicorum Aristotelis et innumerabiles Senecae, et Tullii, et aliorum, et inveniemus quod sumus in abysso vitiorum, ut dicamus, «Gratia Dei salvavit nos». Summus enim zelus castitatis, et mansuetudinis, et patientiae, et constantiae, et omnium virtutum fuit apud philosophos ${ }^{46}$.

${ }^{44}$ Ibíd., p. 133. [«Pero también hay una causa especial por la que me demoro en estos libros de Séneca, y es que aunque los busqué desde mi infancia, con todo, no pude nunca ver los libros De ira, Ad Helviam, Cur bonis mala accidant (De providentia), An in sapientem cadant contumelia et iniuria (De constantia sapientis), Ad Marciam y los tres siguientes (1 De breuitate + Ad Polybium, 2 De uita beata + De otio, 3 De tranquillitate) sino hasta muy recientemente, y no sé si llegaron a las manos de Vuestra Gloria, por lo cual más abundantemente me he dispuesto a escribir aquí»]. Los mismos términos emplea en su Opus tertium: «... in quibus posui sententias multorum librorum Senece, qui sunt optimi et rarissime inueniuntur», Little, ed. cit., p. 61; «libros vero Senecae, quorum flores vestrae beatitudini conscripsi, numquam potui invenire, nisi a tempore mandati vestri [1266], quamvis diligens fui in hac parte jam a viginti annis et pluribus», Brewer, ed. cit., p. 56. [«nunca pude hallar los libros de Seneca, cuya recopilación realicé para Vuestra Santidad, sino a partir de vuestro mandato, a pesar de que me ocupé con diligencia en el asunto por veinte años y más»]. Véase L. Annaei Senecae Dialogorum libri duodecim, ed. de L. D. Reynolds, Oxford, University Press, 1977, p. VII.

${ }^{45}$ Véase Brewer, ed. cit.

${ }^{46} \mathrm{Ibid}$., p. 50. [«La tercera parte versa sobre la honestidad de las virtudes a fin de que sean amadas y de lo vergonzoso de los vicios para que sean evitados; y esta es la más hermosa sabiduría que pueda ser llamada con tal nombre. En efecto, respecto a los cristianos, es admirable que seamos más imperfectos en las costumbres que los filósofos infieles. Léanse los diez libros de la Ética de Aristóteles y los 
Nuevamente el franciscano señala la preeminencia de los antiguos filósofos paganos sobre los cristianos en cuanto a la sabiduría moral y el cultivo de las virtudes. Entre los primeros, señala a Séneca y, de sus obras, el diálogo De ira, capaz de hacer deponer de su pasión, con su sola lectura, a cualquiera que estuviera dominado por la cólera:

Nam non est homo in aliquo vitio ita absorptus quin si legeret diligenter libros hos illud vitium dimitteret; quoniam ita potenter allegant pro qualibet virtute, et contra quodlibet vitium, quod non est finis. Unde cum pessimum vitium sit ira, quia omnem hominem et totum mundum destruit, non est homo ita iracundus qui si videret diligenter libros tres Senecae quin verecundaretur irasci. Mira sapientia in illis libris continetur; et sic in aliis ${ }^{47}$.

La sabiduría manifestada en el De ira y en el resto de las obras de Séneca y de los filósofos de la antigüedad solo pudo haber sido inspirada por Dios:

Et ideo de illis libris de Ira, et de multis aliis conscripsi, in parte hac tertia moralis philosophiae, ut videatur infinita sapientia philosophorum, quoniam postquam Deus iis concessit, potuerunt in aliis praevalere; quia virtus illuminat animum in cognitione veritatis, et peccatum obfuscat ${ }^{48}$.

La misma idea sugiere Bacon en el cap. XXII, en el que se refiere al contenido de la primera parte de su Opus Maius. En su reflexión sobre el hombre que se deja llevar por la opinión y la costumbre de la multitud y no por la razón, introduce una cita de las Cartas a Lucilio $(123,6)^{49}$, que lo lleva al siguiente elogio de Séneca:

\footnotetext{
innumerables de Séneca y de Tulio y de tantos otros, y nos reconoceremos en el abismo de los vicios, como para decir: «la Gracia de Dios nos salvó». Pues en los filósofos se dio en sumo grado el celo por la castidad y por la mansedumbre y por la paciencia y por la constancia y por todas las virtudes»].

${ }^{47}$ Ibíd., pp. 50-51. [«En efecto, no hay hombre alguno tan absorto en un vicio que, si leyera diligentemente estos libros, dejará aquel vicio, puesto que con tanta autoridad argumentan en favor de cualquier virtud y contra cualquier vicio, que no se les puede poner un límite. De allí que, siendo la ira el peor de los vicios, ya que destruye al hombre y al mundo en su totalidad, con todo, no hay hombre tan iracundo que si leyera diligentemente los tres libros de Séneca no sintiera vergüenza por su cólera. En ellos se encuentra admirable sabiduría, y así en los restantes»].

${ }^{48} \mathrm{Ibid}$., p. 51. [«Y por eso, en esta parte de la filosofía moral, hice una compilación de aquellos libros Sobre la ira y de muchos otros para que pueda admirarse la infinita sabiduría de los filósofos, porque, después que les fue concedido por Dios, pudieron sobresalir en otras cuestiones, dado que la virtud ilumina el ánimo en el conocimiento de la verdad y el pecado lo oscurece»].

${ }^{49}$ L. Annaei Senecae ad Lucilium epistulae morales, ed. de L. D. Reynolds, Oxford, University Press, 1965, p. 530.
} 
In tota sapientia theologiae et juris canonici et philosophiae, no est de hac materia tam pulchra sententia, istas tres causas errorum nostrorum colligens in una auctoritate continua. Optimum verbum ete omni sapiente dignum, et ab ipso Deo revelatum ${ }^{50}$.

Y hace suyas las palabras atribuidas a Pablo en su correspondencia, apócrifa, con el filósofo romano:

Unde Apostolus Paulus dicit in epistola ad Senecam: «praeprudenti tibi revelata sunt quae paucis Divinitas concessit ${ }^{5 /}{ }^{1}$.

La misma reverencia hacia Séneca y, de modo particular, hacia el De ira, se pone de manifiesto en el capítulo LXXV. Al referirse a la predicación del Evangelio, destaca la capacidad de persuasión del filósofo estoico para apartar del vicio y encaminar hacia la virtud:

Nam qualiter contingat persuadere de divitiis vitandis et virtutibus exequendis manifesto explicavi per libros Senecae De ira, et in aliis optimis, in quibus inveniuntur ad vitium vel virtutem modi speciales persuadendi; nunc per exempla magnorum sapientum, nunc per rationes, nunc per auctoritates, nunc per similitudines sumptas ex rebus naturalibus et aliis, ita quod nullus est ita sapiens in hoc mundo quin possit mirari de tanta efficacia persuadendi... ${ }^{52}$

Nuevamente el franciscano sostiene que la eficacia persuasiva de las palabras del filósofo reside no solo en su belleza sino principalmente en la coherencia entre discurso y experiencia de vida:

[...] et poterit vestra beatitudo videre tam propios modos arguendi de amore virtutis talis et talis, vel de horrore vitiorum, et tam pulchros, quod non est

\footnotetext{
${ }^{50}$ Brewer, ed. cit., p. 72. «En toda la sabiduría de la teología, del derecho canónico y de la filosofía, no existe un pensamiento tan hermoso sobre este tema que reúna las tres causas de nuestros errores en una autoridad continua. La mejor reflexión y digna de todo sabio, y revelada por Dios mismo».

${ }^{51}$ Ibíd. «De ahí que el Apóstol Pablo le dice en una carta dirigida a Séneca: "a ti, sapientísimo, te fueron reveladas cosas que la Divinidad concedió a unos pocos"». Véase Epistolae Senecae ad Paulum et Pauli ad Senecam «quae vocantur», ed. de Claude W. Barlow, Horn, American Academy in Rome, 1938, p. 137, donde se ofrece la lectura perpendenti en lugar de praeprudenti.

${ }^{52} \mathrm{Ibid}$., p. 305. [«En efecto, expliqué claramente de qué manera se puede persuadir sobre el desprecio de las riquezas y el cultivo de las virtudes por medio de los libros de Séneca Sobre la ira y en otros óptimos en los cuales se encuentran los modos especiales de aconsejar sobre el vicio o sobre la virtud, ya por ejemplos de grandes sabios, ya por razones, ya por autoridades, ya por semejanzas tomadas de la naturaleza y de otras cosas, de modo que ninguno puede llegar a ser tan sabio en este mundo que no pueda admirarse del grado de eficacia en el persuadir...»].
} 
finis. Et certe nunquam fuisset sic philosophi loquuti, nisi quia per experientiam longam habuerunt exercitium virtutis ${ }^{53}$.

La persona misma de Séneca proporciona un ejemplo magnífico de ejercicio de la virtud y preocupación por la vida interior:

Seneca vero refert de seipso, quod omni die antequam in nocte dormiret, totam vitam suam diurnam recoleret, ut videret in quibus verbis et factis aut male fecisset aut minus; dicens in quo gravor si dicam mihi ipsi, vide ne plus feceris hoc, vel dixeris. Et tamen habuit uxorem juxta se, quae non fuit susa impedire eum, sciens, ut ait, meam consuetudinem ${ }^{54}$.

\section{El fragmento editado por Duhem}

Una mención especial merece el fragmento del Opus Tertium editado por primera vez en 1909 por Duhem ${ }^{55}$ y posteriormente, en 1912, por Little ${ }^{56}$. En dicho fragmento Bacon reelabora y especifica las razones que lo llevaron a detenerse en la obra de Séneca. A la vez que valora una vez más la capacidad persuasiva de los filósofos antiguos y, de modo particular, de Séneca, destaca la conveniencia de la materia tratada en sus libros para los prelados y príncipes:

Et quia hic est philosophorum persuasio mirabilis, et utilis, et magnifica, et ignota, ideo copiosius scripsi de hac parte. [...] Scripsi igitur de virtutibus et viciis primo in universali. $2^{\circ}$ descendi ad quedam in particulari, propter gloriosos libros quos inveni. Tractavi igitur ea que pertinent ad mansuetudinem, et clementiam, et magnanimitatem, et de ceteris virtutibus que his conveniunt qui sunt in potestate constituti, qui sun prelati et principes ${ }^{57}$.

${ }^{53}$ Ibíd. [«Y Vuestra Santidad podrá contemplar tantos y tales modos propios de argumentar sobre el amor a la virtud o bien sobre el horror a los vicios y tan hermosos que no tienen límite. Y ciertamente nunca los filósofos habrían hablado así sino porque, por su larga experiencia, se ejercitaron en la virtud.»].

${ }^{54}$ Ibíd., pp. 305-306. [«Ahora bien, Séneca cuenta de sí mismo que todos los días, antes de ir a dormir, por las noches, revisaba cómo había vivido durante el día para ver con qué palabras o acciones había actuado mal o no, diciendo "en qué me arrepiento si lo digo a mí mismo; trata de no hacer o decir más esto..." Y con todo, tuvo una mujer que no se atrevió a impedirle, conociendo, como decía, 'mi costumbre'.»]. Véase Massa, ob. cit., p. 154. La anécdota de Séneca hace referencia a su práctica diaria del «examen de conciencia» (De ira, III, 36).

${ }^{55}$ Pierre Duhem, Un fragment inédit de l'Opus tertium de Roger Bacon précédé d'une étude sur ce fragment, Ad Aquas Claras: Ex Typografia Collegii S. Bonaventurae, 1909.

${ }^{56}$ Little, ed. cit.

${ }^{57}$ Ibid., p. 60. «Y puesto que esta persuasión de los filósofos es admirable, útil, magnífica y desconocida [hablando principalmente de las obras de Séneca], por eso con mayor profusión escribí a partir de esta sección. [...] Por tanto, he escrito sobre las virtudes y los vicios primero en general, $2^{\circ}$ descendí a algunos en particular, a causa de los gloriosos libros que encontré. En consecuencia, he tratado aquellas cuestiones correspondientes a la mansedumbre, a la clemencia y a la magnanimidad, y acerca de las 
En su justificación, al descubrimiento de los nobiliores libros se suma el hecho de que la obra esté dirigida al Papa:

Cujus causa duplex fuit: Una quod nobiliores libros reperi de hac materia. Alia est quod scribo illi qui omnibus prelatis et principibus suprafertur, et omnes habet regere, et omnibus consulere, et cunctos reducere ad regimen populi pacificum et salubre ${ }^{58}$.

De esta manera Bacon concibe su obra como un verdadero Speculum principum destinado a la educación de aquellos que ejercen el poder. Precisamente es en ellos en quienes la ira se muestra más nociva y, en vista de los efectos que provoca en los hombres, se extiende más en su exposición, fundamentándose en el filósofo estoico, como explica a continuación:

Et quia vicium maxime repugnans illis qui presunt est ira, quia tollit omnem virtutem que est necessaria regimini; et ubi ira cum potestate est, omnia pereunt, ut vult Seneca; et videmus propter iram cum potestate totum mundum turbari, et omnem rem publicam quassari, et omne regnum desolari, ideo scripsi habundancius de hac materia. Et non solum propter hoc, sed quia fere omnem hominem deducit hoc vicium ad perniciem, et cogit rumpere pacem cum omnibus, etiam cum amicissimis. Nam iratus non parcit patri, nec matri, nec domino, nec amigo; sed omnes dehonestat contumeliis, omnes impetit injuriis, et seipsum periculis quibuslibet exponere non omittit, et Deum blasphemare non veretur. Hoc igitur est vicium per quod homo amittit seipsum, et proximum, et Deum. Et ideo philosophi scripserunt plus de hoc vicio quam de aliis. Inter quos elegantissimus philosophus Seneca conscripsit tres libros nobiles, quorum sententiam collegi diligenter, addens alia de libris suis et aliorum ${ }^{59}$.

restantes virtudes que convienen a aquellos que están constituidos en autoridad como son los prelados y príncipes»].

${ }^{58}$ Ibíd. [«La causa de ello fue doble: una, haber encontrado libros más nobles sobre esta materia; otra, que escribo a aquel que está puesto por encima de todos los prelados y príncipes, y tiene la obligación de regir a todos y aconsejar a todos, y conducirlos en su totalidad al gobierno pacífico y saludable del pueblo»].

${ }^{59} \mathrm{Ibid}$., pp. 60-61. [«Y porque la ira es el vicio más incompatible con aquellos que gobiernan, ya que elimina toda virtud necesaria para el gobierno, y cuando la ira tiene poder todos perecen, como dice Séneca; y vemos que a causa de la ira con poder todo el mundo es turbado y todo estado agitado y todo reino desolado, por todo ello, he decidido escribir con más profusión sobre el tema. Y no solo por esto, sino porque este vicio arrastra a casi todo hombre a su perdición y lo fuerza a quebrantar la paz con los demás hombres, incluso con los más amigos. En efecto, el colérico no perdona ni a su padre, ni a su madre, ni a su señor, ni a su amigo, antes bien, a todos deshonra con ultrajes, a todos ataca con injurias y no deja de exponerse a sí mismo a cualquier peligro y no teme incluso a blasfemar contra Dios. Por tanto, este es un vicio que lleva al hombre a perderse a sí mismo, al prójimo y a Dios. Y por eso los filósofos escribieron más sobre este vicio que sobre los otros. Entre los cuales, el elocuentísimo filósofo Séneca compuso tres nobles libros, cuyo pensamiento compilé diligentemente, añadiendo otras citas de sus libros y de otros autores»]. 
El pasaje se cierra con una nueva reflexión de Séneca en torno a los efectos de la lectura del De ira en aquellos que padecen tan terrible pasión:

Et certus sum quod non est homo mortalis tam iracundus quin abhorreret irasci, si in promptu haberet sensum eorum que scripsi. Quia tanta potestate rationum pulcrarum, auctoritatum solemnium, exemplorum sublimium vallata sunt, per Senecam maxime, quod omnem hominem cogerent ad mansuetudinem, et clementiam, et ad omnem humanitatem ${ }^{60}$.

\section{Roger Bacon y el Libro contra la ira e saña: algunas coincidencias}

Con unos años de diferencia, encontramos la misma devoción por Séneca que Bacon profesa en su obra en la traducción castellana anónima del De ira dedicada a Sancho IV (1258-1295) con el título de Libro de Séneca contra la ira e saña. La versión romance, conservada en tres manuscritos escurialen$\operatorname{ses}^{61}$, está precedida de un prólogo que exalta la figura de Séneca:

Séneca, doctíssimo onbre en toda facultad de ciencia, especialmente en la moral filosofía, tanto que ninguno igual d'él se falla por alguno de aquellos que sus escripturas examinaron. E fue onbre de buena vida e tan continente que dize Sant Jerónimo debié ser puesto en el catálago de los Santos. Et por quanto la filosofía moral es de mayor utilidad que ninguna de las otras ciencias, fizo muchos libros de aquella, entre los cuales ordenó por singular este que es intitulado contra ira e saña. Et fízolo a provecho de todos uniuersal, e más señaladamente para los prínçipes e grandes señores, porque en los semejantes la ira e saña es muy más peligrosa... (Esc. N.II.8, ff. 1r-1va)

Como señalan González Rolán y López Fonseca ${ }^{62}$, el prólogo de la traducción presenta la forma de accesus ad Senecam articulado en cuatro partes: nomen auctoris, titulus operis, utilitas siue finalis causa y numerus et ordo

\footnotetext{
${ }^{60}$ Ibíd., p. 61. [«Estoy seguro de que no hay hombre mortal tan iracundo que no sienta aversión a la ira, si tuviera a disposición aquellos pensamientos que puse por escrito. Porque es tal la virtud de la hermosura de sus razones, la solemnidad de sus autoridades y la sublimidad de sus ejemplos procedentes, principalmente, de Séneca que obligaría a todo hombre a la mansedumbre, a la clemencia y a toda humanidad»].

${ }^{61}$ Mss. Esc. N.II.8, S.II.14 y T.III.3. Para una descripción detallada de los mismos véase Juan Héctor Fuentes, «Presupuestos ecdóticos para una edición crítica del Libro de Séneca contra la yra e saña», en Miscellanea Philologica, Lecturas de textos latinos clásicos en manuscritos, ediciones, comentarios y traducciones de los siglos XII a XX, ed. de María Eugenia Steinberg, Buenos Aires, Editorial de la Facultad de Filosofía y Letras, Universidad de Buenos Aires, 2011, pp. 11-23.

${ }^{62}$ Tomás González Rolán y Antonio López Fonseca, Traducción y elementos paratextuales: los prólogos a las versiones castellanas de textos latinos en el siglo XV. Introducción general, edición y estudio, Madrid, Escolar y Mayo, 2014, pp. 327-328.
} 
librorum. La primera parte del accesus destaca la sabiduría de Séneca y, específicamente, su pertenencia a la filosofía moral: «Séneca, doctíssimo onbre en toda facultad de ciencia, especialmente en la moral filosofía, tanto que ninguno igual d'él se falla por alguno de aquellos que sus escripturas examinaron». A continuación, cita un pasaje del De viris illustribus de San Jerónimo en el que se destaca la vida virtuosa del filósofo al punto de considerarlo un santo cristiano más: «E fue onbre de buena vida e tan continente que dize Sant Jerónimo debié ser puesto en el catálago de los Santos.» ${ }^{63}$. En el titulus operis incluye, además del título del tratado, Contra ira e saña, una observación sobre la filosofía moral: «E por quanto la filosofía moral es de mayor utilidad que ninguna de la las otras ciencias, fizo muchos libros de aquella, entre las cuales ordenó por singular este...». Antes de pasar al numerus et ordo librorum, presenta la utilitas siue finalis causa: «E fízolo a provecho de todos universal e más señaladamente para los prínçipes e grandes señores, porque en los semejantes la ira e saña es muy más peligrosa...».

Si atendemos a cada una de las partes del accesus, podemos advertir que el contenido presente en ellas coincide con la valoración de Bacon sobre Séneca, el De ira y el lugar de la moralis philosophia en su sistema filosófico. Asimismo, la preocupación por los efectos negativos de la pasión en los prínçipes y grandes señores se ajusta a las observaciones que el Doctor Mirabilis realiza a lo largo de las obras estudiadas anteriormente.

La concomitancia excede el plano del contenido y se proyecta al plano formal: frente al texto del De ira tanto Bacon como el traductor anónimo adoptan la forma tractatus y apelan a la práctica de la compilatio, aunque los criterios utilizados son diversos ${ }^{64}$ : en la Moralis philosophia sigue el esquema organizativo de la distinctio, distribuido en un proemio y nueve capítulos en los que el franciscano compila pasajes del De ira, sin atender a qué libro pertenecen,

${ }^{63}$ El autor del accesus toma del cap. XII del De viris inlustribus de San Jerónimo la observación sobre la vida continente de Séneca y la voluntad de inclusión del filósofo en el catálogo de los Santos: «Lucius AnNAEus SenECA Cordubensis, Sotionis stoici dsicipulus et patruus Lucani poetae, continentissimae vitae fuit, quem non ponerem in catalogo sanctorum nisi me illae Epistulae provocarent, quae leguntur a plurimis Pauli ad Senecam et Senecae ad Paulum...» (Hieronymus De viris inlustribus, Gennadius De viris inlustribus, ed. de Ernest Richardson, Leipzig, J. C. Hinrich'sche Buchhandlung, 1896, p. 15). [«Lucio Anneo Séneca, Cordobés, discípulo del estoico Soción y tío paterno del poeta Lucano, fue de una vida muy continente, a quien no incluiría en el catálogo de los Santos si no me motivaran a ello aquellas famosas cartas que muchos leen de Pablo a Séneca y de Séneca a Pablo»]. El pasaje es citado también por Juan Gil de Zamora en su De preconiis Hispanie, en el capítulo sobre los filósofos de España, véase Fray Juan Gil de Zamora, O.F.M., De preconiis Hispanie, ed. de Manuel de Castro y Castro, O.F.M., Madrid, Universidad, 1955, p. 178.

${ }^{64}$ Sobre la práctica de la compilatio y el discurso compilatorio en el siglo XIII, véase Olga Soledad Bohdziewicz, «El Liber Mariae de Juan Gil de Zamora y el discurso compilatorio», en Studia Zamorensia, 13 (2014), pp. 95-107. 
de otras obras de Séneca y, en una proporción mucho menor, de otros autores. De esta manera, el franciscano enmarca la ira entre los pecados y desarrolla su oposición a la naturaleza humana (cap. 1) y a las virtudes (caps. 2-4); explica cómo sobrepasa al resto de los pecados (caps. 5-7) y propone los remedios convenientes (caps. 8-9). El Libro de Séneca contra la ira e saña, en cambio, se divide en tres libros como el original latino, pero presenta un reordenamiento del material textual siguiendo, probablemente, las indicaciones marginales del modelo latino utilizado, que habrían servido de guía de lectura y de exposición del texto. Incluso algunas de esas notas habrían sido incorporadas a la traducción, como sugiere la comparación de la intentio operis y la divisio textus que se encuentra en una anotación del margen inferior del ms. Bnf lat. 6390, f. 49r con la sección final del accesus de la versión romance en la que se señala el ordo et numerus librorum ${ }^{65}$ :

Huius primi libri intentionem potes in quinque diuidere partes: in prima, ire diffinitionem; in $2^{\mathrm{a}}$ ibi CONTRA UTRAMQUe [De ira, I, 3, 3] probat iram in nullum aliud animal quam in hominem cadere; in $3^{\mathrm{a}}$ ibi QUID ESSET [De ira, I, 4, 1] ostendit in quo ira distet $\mathrm{ab}$ iracundia et quae sint ire species; in $4^{\mathrm{a}}$ ibi NUNC QUERAMUS [De ira, $\mathrm{I}$, $5,1]$ probat iram non esse secundum hominis naturam; in $5^{\mathrm{a}}$ probat eam non esse utilem uel necessariam uel ex aliqua parte retinendam ibi NUMQUID QUAMUIS [De ira, I, 7, 1]. (ms. Bnfr lat. 6390, f. 49r)
E pártesse en tres libros. El primero d'ellos partiolo en siete partes: la primera muestra qué cosa es ira e cómo es peor que todas las otras voluntades malas e cuántos et cuáles males vienen d'ella. En la segunda, muestra cómo es mouimiento malo en el onbre tan solamente e non en otro animal. En la terçera, muestra qué distinçión ay entre ira e saña, e cuáles e cuántas maneras son d'ella. En la cuarta, muestra cómo la ira non es en el honbre segunt su natura, mas por yerro e maldad et cómo el castigo de los malos non se ha de fazer con ira nin por saña nin son menester ninguna d'estas cosas para ello, mas hase de fazer por razón, con buen entendimiento, porque así cumple a esto e non ál. La quinta muestra de cómo ira nin ninguna mala voluntad non se pueden tenplar después que onbre cae en cada una dellas. En la sesta, muestra generalmente que la ira en ninguna cosa non es provechosa. En la séptima dize que la yra non aprouecha a grandeza nin a esfuerço de coraçón, como algunos dixeron. (ms. Esc. N.II.8, ff. 1va-2ra)

\footnotetext{
${ }^{65}$ En un artículo anterior estudiamos la disposición de la traducción castellana en relación con las notas marginales y argumentos presentes en BnF ms. Latin 6390. Véase Fuentes, art. cit., 2016.
} 
El romanceamiento castellano está organizado, como hemos dicho, en tres libros. El primero, a su vez, está distribuido en siete «Partes» que incorporan distintos pasajes de De ira, I; el segundo libro, en el que se observan los cambios más significativos, está organizado en dos «Partes principales», cada una con su respectivo prólogo: la primera incluye nueve cuestiones y en ella se reúnen todas las secuencias de los libros I y II del De ira que el traductor identificó con la forma de la quaestio escolástica; la segunda parte principal, dividida en capítulos, reproduce De ira, II, 18 a 36; el libro tercero está dedicado a los remedios contra la ira, es el más extenso y el que menos reelaboración presenta respecto del original latino al incorporar casi la totalidad de De ira, III $^{66}$. Como podemos apreciar, el grado de reelaboración en el Libro de Séneca contra la ira e saña es mucho menor que el de la Distinctio tercia del Opus maius, VII, III.

Una mención especial merece la sección final del prólogo de la traducción romance. A continuación de la divisio textus del libro primero encontramos una invocación a Dios y a la Santísima Virgen María seguida de una dedicatoria:

En el nonbre del eterno Dios, el cual es Causa de las causas et Fazedor de todas aquellas, e al honor e gloria de la Virgen María, su Madre, fiando e aviendo esperança en la su grant piedad e bondad de que todo bien viene que mejorará e acrescentará a acabar nuestro buen desseo, al pro común de todos, señaladamente a serviçio de nuestro señor, el rey don Sancho, començaremos la traslaçión deste libro que dize assí (ms. Esc. N.II.8, f. 2ra)

La crítica ha coincidido en identificar al «rey don Sancho» con Sancho IV a quien se le aplicó el apelativo de «Bravo» no por su valentía, como podría suponerse, sino por su carácter colérico ${ }^{67}$. Aunque Ruiz García ponga en duda que la obra haya sido compuesta «por la oportunidad del asunto tratado» ${ }^{68}$, no deja de ser sugerente que el traductor o el promotor de la versión romance haya tenido presente la pasión dominante del monarca castellano y haya

${ }^{66}$ Para un estudio detallado de la distribución de los pasajes del De ira en los libros de Libro contra ira e saña, véase Fuentes, art. cit., 2016.

${ }^{67}$ Véase Mercedes Gaibrois de Ballesteros, Sancho IV de Castilla, tomo 1, Madrid, Tip. de la Revista de Archivos, 1922, p. 23, y tomo II, Madrid, Talleres «Voluntad», 1928, pp. 14-15. Para la etimología de bravo $\leftarrow$ lat. pravus, en Rafael Lapesa, Historia de la lengua española, Madrid, Gredos, 1980, pp. 104-105.

${ }^{68}$ Elisa Ruiz García, «Rex scribens: discurso de la conflictividad en Castilla (1230-1350)» en La monarquía como conflicto en la corona castellano-leonesa (c. 1230-1504), ed. de José Manuel Nieto Soria, Madrid, Sílex, 2006, pp. 359-422, esp. 406-407. 
buscado para ella la «terapéutica racional» que ofrecía el diálogo ${ }^{69}$, concebido este como «espejo de príncipes», «porque en los semejantes la ira e saña es muy más peligrosa». No podríamos precisar si el autor del romanceamiento conoció la obra de Bacon, pero consciente o inconscientemente siguió el consejo que el franciscano enderezó al pontífice cuando afirmaba «non est homo ita iracundus qui si videret diligenter libros tres Senecae quin verecundaretur irasci. Mira sapientia in illis libris continetur...».

\section{Conclusión}

Elogio y cristianización de la figura de Séneca, exaltación de la filosofía moral, atención a la educación de príncipes y prelados, preocupación por los efectos de la ira, práctica compilatoria... Todos estos aspectos que se encuentran en el Libro de Séneca contra la ira e saña están presentes ya a lo largo de la obra del franciscano inglés. Si atendemos al hecho de que los frailes peninsulares realizaban parte de su formación en París ${ }^{70}$, de que Roger Bacon llegó a tomar contacto con estudiantes españoles ${ }^{71}$ y de que, entre otros, Juan Gil de Zamora habría recibido su formación en París en una fecha muy próxima al momento en que el Doctor Mirabilis anunciara al Papa Clemente IV el descubrimiento de los Diálogos $^{72}$, no resultaría extraño que las opiniones del franciscano inglés y una copia del De ira llegaran a la Península a través de

\footnotetext{
${ }^{69}$ Para el carácter terapéutico del diálogo, véase Janine Fillion-Lahille, Le 'De ira' de Sénèque et la philosophie stö̈cienne des passions, Paris, Klincksieck, 1984, y «La production littéraire de Sénèque sous les règnes de Caligula et de Claude, sens philosophique et portée politique: les 'Consolations' et le De ira», en Aufstieg und Niedergang der Römischen Welt. Teil II : Principat. Band 36: Philosophie, Wissenschaften, Technik. 3. Teilband : Philosophie (Stoizismus), Berlin-New York, Walter de Gruyter, 1989, pp. 1607-1638.

${ }^{70}$ Véase Juan Gil de Zamora, Liber contra venena et animalia venenosa, ed. de Cándida Ferrero Hernández, Barcelona: Reial Acàdemia de Bones Lletres, 2009, pp. 26-27 y Bert Roest, Franciscan Learning, Preaching and Mission c. 1220-1650. Cum scientia sit donum Dei, armatura ad defendendam sanctam fidem catholicam, Brill, Leiden-Boston, 2014, pp. 52-57.

${ }^{71}$ Recuérdese la anécdota detallada por el mismo Bacon en la que refiere cómo un grupo de estudiantes peninsulares le aclara el sentido de la palabra beleño. Véase Antoine Thomas, «Roger Bacon et les étudiants espagnols», en Bulletin Hispanique, 6:1 (1904), pp. 18-28; Castro y Castro, ed. cit., p. LXII; y Amanda Power, ob. cit., p. 37.

${ }^{72}$ Castro y Castro, ed. cit., pp. LXIII-LXVII, fecha el inicio de sus estudios en París entre 1272 y 1273 y su retorno en 1278. Ferrero Hernández, ed. cit., pp. 38-39, manifiesta su escepticismo sobre la datación de los estudios de Juan Gil en París y no descarta la posiblidad de adelantarla dos décadas. Un estado de la cuestión en Juan Gil de Zamora, Legende Sanctorum et festivitatum aliarum de quibus Ecclesia sollempnizat. Leyendas de los Santos y de otras festividades que celebra la Iglesia, ed. de José Carlos Martín Iglesias y Eduardo Otero Pereira, Zamora, Instituto de Estudios Zamoranos «Florián de Ocampo», 2014, pp. 14-16.
} 
algún miembro de su orden ${ }^{73}$. La hipótesis se torna más verosímil si se tiene en cuenta el vínculo que habría existido entre el Sancho IV y el franciscano de Zamora, a quien algunos consideran preceptor e incluso confesor del infante y luego monarca castellano ${ }^{74}$.

Con todo, al no encontrar datos más precisos solo podemos limitarnos a señalar estas concomitancias que nos remiten al clima intelectual que generaron las órdenes mendicantes y, de modo particular, la red escolar franciscana establecida prácticamente en toda Europa que tuvo en el Studium generale de París su foco de irradiación principal ${ }^{75}$. De esta manera, el Libro de Séneca contra ira e saña se nos ofrece como la respuesta peninsular y la concreción en lengua romance de los consejos del fraile inglés ante «la más oscura y rabiosa de todas las pasiones» ${ }^{76}$.

Recibido: 22/05/2018

Aceptado: 17/07/2018

${ }^{73}$ Durante su estadía en París Juan Gil habría entrado en contacto con Fray Raimundo de Geoffroi, muy cercano a Roger Bacon, a quien dedica su Liber contra venena. Véase Castro y Castro, ed. cit., pp. LXIII-LXIV; Ferrero Hernández, ed. cit., pp. 40-41.

${ }^{74}$ Véase Castro y Castro, ed. cit., pp. XC-XCI, y Martín Iglesias-Otero Pereira quienes consideran que el magisterio de Juan Gil sobre Sancho IV «debió de ejercerse simplemente a través de los escritos que Gil de Zamora compuso para el Infante, y no por medio de una relación directa continuada» (ed. cit., p. 17).

${ }^{75} \mathrm{Al}$ respecto, véase Bert Roest, A History of Franciscan Education (c. 1210-1517), Leiden-BostonKöln, Brill, 2000, pp. 11-42.

${ }^{76}$ Séneca, De ira, I, 1. 


\section{$\cos 8$}

\section{Roger Bacon, el diálogo DE IRA DE SÉNeCA y el Libro CONTRA LA IRA E SAÑa}

RESUMEN: El presente artículo estudia las relaciones que pueden establecerse entre el Libro de Séneca contra la yra e saña, traducción medieval del diálogo De ira de Séneca dedicada a Sancho IV de Castilla, y el franciscano Roger Bacon (1214/12201292), llamado Doctor Mirabilis. Las opiniones sobre Séneca y su diálogo vertidas por Bacon en sus obras, principalmente en su Opus maius y su Opus tertium, coinciden con las ideas presentes en el prólogo de la traducción castellana en lo que respecta a la valoración del filósofo, el lugar de la filosofía moral, los efectos perniciosos de la pasión y la importancia de la educación de los príncipes.

Palabras Clave: Séneca. Roger Bacon. De ira. Libro contra la ira e saña. Traducción medieval.

\section{Roger Bacon, SenecA's dialogue DE IRA AND the Libro CONTRA LA IRA E SAÑA}

ABSTRACT: The present article studies the relationships that can be established between the Libro de Séneca contra la ira e saña, medieval translation of Seneca's dialogue On anger dedicated to Sancho IV of Castile, and the Franciscan Roger Bacon (1214/1220-1292), called Doctor Mirabilis. The opinions on Seneca and his dialogue proposed by Bacon in his works, mainly in his Opus maius and his Opus tertium, coincide with the ideas contained in the prologue of the Castilian translation in regard to the assessment of the philosopher, the place of moral philosophy, the pernicious effects of passion and the importance of the princes' education.

KeYwords: Seneca. Roger Bacon. De ira. Libro contra la ira e saña. Medieval Translation. 